\title{
Skin autofluorescence predicts new cardiovascular disease and mortality in people with type 2 diabetes
}

Henderikus E. Boersma ${ }^{1,2}$, Robert P. van Waateringe ${ }^{1}$, Melanie M. van der Klauw ${ }^{1}$, Reindert Graaff ${ }^{1}$, Andrew D. Paterson ${ }^{3}$, Andries J. Smit ${ }^{2}$ and Bruce H. R. Wolffenbuttel ${ }^{1^{*}}$ (i)

\begin{abstract}
Background: Skin autofluorescence (SAF) is a non-invasive marker of tissue accumulation of advanced glycation endproducts (AGE). Recently, we demonstrated in the general population that elevated SAF levels predict the development of type 2 diabetes (T2D), cardiovascular disease (CVD) and mortality. We evaluated whether elevated SAF may predict the development of CVD and mortality in individuals with T2D.

Methods: We included 2349 people with T2D, available baseline SAF measurements (measured with the AGE reader) and follow-up data from the Lifelines Cohort Study. Of them, 2071 had no clinical CVD at baseline. 60\% were already diagnosed with diabetes (median duration 5, IQR 2-9 years), while 40\% were detected during the baseline examination by elevated fasting blood glucose $\geq 7.0 \mathrm{mmol} / \mathrm{l})$ and $/$ or $\mathrm{HbA} 1 \mathrm{c} \geq 6.5 \%(48 \mathrm{mmol} / \mathrm{mol})$.
\end{abstract}

Results: Mean ( \pm SD) age was $57 \pm 12 \mathrm{yrs}$., BMI $30.2 \pm 5.4 \mathrm{~kg} / \mathrm{m}^{2} .11 \%$ of participants with known T2D were treated with diet, the others used oral glucose-lowering medication, with or without insulin; $6 \%$ was using insulin alone. Participants with known T2D had higher SAF than those with newly-detected T2D (SAF Z-score $0.56 \pm 0.99$ vs $0.34 \pm 0.89 \mathrm{AU}, p<0.001$ ), which reflects a longer duration of hyperglycaemia in the former group. Participants with existing CVD and T2D had the highest SAF Z-score: $0.78 \pm 1.25$ AU. During a median follow-up of 3.7 yrs., 195 (7.6\%) developed an atherosclerotic CVD event, while 137 (5.4\%) died. SAF was strongly associated with the combined outcome of a new CVD event or mortality (OR 2.59, 95\% Cl 2.10-3.20, $p<0.001$ ), as well as incidence of CVD (OR $2.05,95 \% \mathrm{Cl} 1.61-2.61, p<0.001)$ and death (OR 2.98, 2.25-3.94, $p<0.001)$ as a single outcome. In multivariable analysis for the combined endpoint, SAF retained its significance when sex, systolic blood pressure, HbA1c, total cholesterol, eGFR, as well as antihypertensive and statin medication were included. In a similar multivariable model, SAF was independently associated with mortality as a single outcome, but not with incident CVD.

Conclusions: Measuring SAF can assist in prediction of incident cardiovascular disease and mortality in individuals with T2D. SAF showed a stronger association with future CVD events and mortality than cholesterol or blood pressure levels.

Keywords: Ageing, Cardiovascular disease, Diabetes, Mortality, Prediction, Skin autofluorescence

\footnotetext{
*Correspondence: bwo@umcg.nl

'Department of Endocrinology, University of Groningen, University Medical

Center Groningen, P.O. Box 30001, HPC AA31, Groningen, RB 9700, The Netherlands

Full list of author information is available at the end of the article
}

(C) The Author(s). 2021 Open Access This article is licensed under a Creative Commons Attribution 4.0 International License, which permits use, sharing, adaptation, distribution and reproduction in any medium or format, as long as you give appropriate credit to the original author(s) and the source, provide a link to the Creative Commons licence, and indicate if changes were made. The images or other third party material in this article are included in the article's Creative Commons licence, unless indicated otherwise in a credit line to the material. If material is not included in the article's Creative Commons licence and your intended use is not permitted by statutory regulation or exceeds the permitted use, you will need to obtain permission directly from the copyright holder. To view a copy of this licence, visit http://creativecommons.org/licenses/by/4.0/ The Creative Commons Public Domain Dedication waiver (http://creativecommons.org/publicdomain/zero/1.0/) applies to the data made available in this article, unless otherwise stated in a credit line to the data. 


\section{Background}

Cardiovascular complications are an important cause of diabetes-related morbidity and excess mortality [1-3]. Various risk factors, such as obesity, and blood pressure (BP) levels, lipids and glycaemic parameters predict the development of cardiovascular disease (CVD). In the past, a variety of risk scores has been developed to assist in adequate disease prediction [4-7].

In the pathophysiology of diabetes-related complications, the role of the accumulation of advanced glycation endproducts (AGEs) has been well established. These AGEs are formed in a complex biochemical process, by glycation of proteins and lipids in the classic Maillard 'browning' reaction, but also by the interaction of amino groups of proteins with $\alpha$-dicarbonyl compounds like as glyoxal, methylglyoxal and 3-deoxyglucosone [8-10]. Crosslinking of AGEs and tissue proteins in the body, may cause for instance an increase of vascular stiffness, elevated blood pressure and limited joint mobility [11, 12]. Binding of circulating AGEs to specific receptors (i.e. the receptors for AGEs [RAGE]) and subsequent uptake in arterial walls may play an important role in the development and progression of atherosclerosis [13, 14].

The accumulation of AGEs can be evaluated by measuring skin autofluorescence (SAF) [15]. This noninvasive method has been described and validated extensively, and it has been shown that SAF strongly correlates with the levels of AGEs in skin biopsies [16]. Earlier studies have shown that SAF is higher in individuals with type 2 diabetes compared with healthy individuals $[17,18]$, and is associated with the development of cardiovascular complications and mortality in these patients $[17,19-21]$. An earlier study by our group in the general population has shown that SAF is a strong predictor of type 2 diabetes and cardiovascular disease, as well as mortality, independent of several classic risk factors [22].

The aim of the present study was to evaluate whether SAF is able to predict the development of cardiovascular disease and mortality in individuals with type 2 diabetes, who participated in the Lifelines Cohort Study.

\section{Methods \\ Participants}

We evaluated participants with type 2 diabetes who participated between 2007 and 2013 in the Lifelines Cohort Study. Lifelines is a large population-based study of residents living in the northern provinces of the Netherlands [23]. At baseline evaluation, both extensive questionnaire and physical examination data were collected [24]. The study was approved by the Medical Ethics Review Committee of the University Medical Center Groningen. All participants provided written informed consent.
Presence of type 2 diabetes was self-reported or based on the use of blood-glucose-lowering medication (oral agents and/or insulin), or fasting blood glucose $\geq 7.0$ $\mathrm{mmol} / \mathrm{l}$ and/or $\mathrm{HbA} 1 \mathrm{c} \geq 6.5 \%(48 \mathrm{mmol} / \mathrm{mol})$ at laboratory evaluation. We did not include participants who, at baseline, reported type 1 diabetes $(n=366)$ or MODY $(n=9)$, or previously having gestational diabetes $(n=$ 266). In 2554 out of 4992 people with type 2 diabetes, validated baseline SAF measurement were available (Supplemental Fig. 1). Participants with available SAF measurements did not differ in sex ratio, age, glucose and $\mathrm{HbA}_{1 \mathrm{c}}$ from those without SAF measurements. Follow-up data were available for 2349 individuals. Of these, 1863 completed the follow-up questionnaires and additional laboratory testing between 2014 and 2018. Of the remaining 486 individuals only interim questionnaire results were available. Duration of follow-up was 3.7 (range 0.5-10) years and comprised 8637 participantyears. In the 1863 participants with complete questionnaire and laboratory data, median follow-up was 4.0 years.

\section{Clinical examination}

Information on medical history, health status and lifestyle including smoking habits were collected using selfadministered questionnaires as published previously (22). Smoking status was classified into never, former or current smoking. The use of medication was verified using the ATC (Anatomical Therapeutic Chemical) Classification System by a research assistant at the baseline investigation only. Weight, height and waist circumference were measured while participants were wearing light clothing and no shoes. Blood pressure and heart rate were measured using an automated Dinamap monitor (GE Healthcare, Freiburg, Germany), for a total of 10 measurements every $10 \mathrm{~min}$, and $\mathrm{BP}$ and heart rate were determined as the average of the last three readings.

\section{Skin autofluorescence}

At baseline, SAF, expressed in arbitrary units, was measured at the forearm using an AGE Reader (Diagnoptics Technologies, Groningen, the Netherlands), as described previously $[18,22,25]$. We calculated SAF Z-scores (adjusted for age) based on the total Lifelines population, separately in men and women.

\section{Biochemical measurements}

Blood was drawn between 8 and 10 a.m. while participants were in the fasting state. For the current study, baseline biochemical measurements used for analysis were performed the same day. $\mathrm{HbA}_{1 \mathrm{c}}$ was measured in EDTA-anticoagulated blood on a Cobas Integra 800 CTS analyser (Roche, The Netherlands) with a NGSP (National Glycohemoglobin Standardized Program) 
certified turbidimetric immunoassay. Blood glucose was measured with a hexokinase method. Serum concentrations of creatinine and lipids (total-, HDL- and LDLcholesterol, and triacylglycerol were measured on a Roche Modular P chemistry analyser (Roche, Basel, Switzerland) [22]. Estimated (e) GFR was calculated using the CKD-EPI (Chronic Kidney Disease Epidemiology Collaboration) formula [26].

\section{Calculations, definitions and statistical analyses}

Baseline as well as new events of cardiovascular disease were defined as a previous or an incident of myocardial infarction, transient ischaemic attack (TIA), cerebrovascular accident (CVA), intermittent claudication or therapeutic intervention including percutaneous transluminal coronary angioplasty (PTCA) with or without stent, coronary artery bypass grafting (CABG) or peripheral vascular surgery. All clinical outcomes were self-reported. Vital status was confirmed with the municipal administration. This database does not contain information on the cause of death. For all age groups, the incidence of cardiovascular disease and all-cause mortality was calculated for all predefined age decades separately and as a composite outcome.

Normally-distributed data are presented as mean $\pm \mathrm{SD}$, otherwise median and interquartile range (IQR) was used. The difference between groups were evaluated with analysis of variance (ANOVA) or the Mann-Whitney $U$ test. The $\chi^{2}$ test was used to analyse categorical variables. Univariable and multivariable logistic regression analysis was used to evaluate the association between SAF and the composite outcome of cardiovascular disease and mortality, with adjustment for the most important baseline variables. A second model was constructed in which only significant variables were included. We did this for the entire type 2 diabetes population, and separately for those individuals with diabetes without clinically manifest cardiovascular disease at baseline. Analyses were conducted with PASW Statistics (Version 23, IBM, Armonk, NY, USA). P-values $<0.05$ were considered statistically significant.

\section{Results}

\section{Baseline characteristics}

At baseline, 1318 subjects reported a previous diagnosis of type 2 diabetes ('known type 2 diabetes'), and their estimated duration of diabetes in these participants was 5 (IQR 2-9) years. In addition, 1031 participants were found to have elevated fasting blood glucose and/or HbA1c at laboratory evaluation, and those individuals were considered as new type 2 diabetes. They were notified of the findings and the laboratory results were reported to the general practitioner. Only $11 \%$ of the participants with known type 2 diabetes were treated with diet, 83\% was treated with oral glucose-lowering agents, with or without insulin, while $6 \%$ was using insulin alone. Individuals with known type 2 diabetes were older than those with new type 2 diabetes $(58.7 \pm 10.8$ years vs $55.0 \pm 12.0$ years, $p<0.001)$. They also had a higher $\mathrm{BMI}$ and $\mathrm{HbA}_{1 \mathrm{c}}$ (all $p<0.01$, Table 1 ), and a larger percentage of them were reporting the use of bloodpressure-lowering medication and/or statins, and they had lower total and LDL-cholesterol. Participants with newly-detected type 2 diabetes had lower SAF levels than those with known diabetes (SAF Z-score 0.34 \pm 0.89 vs $0.56 \pm 0.99 \mathrm{AU}, p<0.001$, Table 1$)$. In Fig. 1 , we show the age-corrected SAF levels for participants with and without cardiovascular disease, in comparison with Lifelines participants without diabetes. SAF Z-scores were the highest in participants with both existing diabetes and cardiovascular disease: $0.78 \pm 1.10 \mathrm{AU}$ (Fig. 1).

In total, 195 individuals (7.6\%) had developed a new CVD event at follow-up. Those with new CVD events were significantly older at baseline $(62 \pm 11$ vs $56 \pm 12$ yrs., $p<0.01)$, and had a lower eGFR $(85 \pm 16$ vs $90 \pm 16$ $\left.\mathrm{ml} / \mathrm{min} / 1.73 \mathrm{~m}^{2}, p<0.001\right)$ compared to those without new CVD events. Levels of blood pressure, serum lipids

Table 1 Clinical characteristics of the study population at baseline

\begin{tabular}{|c|c|c|c|}
\hline Characteristic & New T2D & Known T2D & $P$-value \\
\hline Sex ( $n$; male/female) & $569 / 462$ & $656 / 662$ & 0.009 \\
\hline Age (years) & $55.0 \pm 12.0$ & $58.7 \pm 10.8$ & $<0.001$ \\
\hline $\mathrm{BMI}\left(\mathrm{kg} / \mathrm{m}^{2}\right)$ & $29.9 \pm 5.2$ & $30.5 \pm 5.5$ & 0.009 \\
\hline Waist (cm) & $103 \pm 13$ & $104 \pm 14$ & 0.009 \\
\hline Systolic BP (mmHg) & $136 \pm 17$ & $135 \pm 17$ & 0.103 \\
\hline Diastolic BP (mmHg) & $78 \pm 10$ & $75 \pm 9$ & $<0.001$ \\
\hline Heart rate (bpm) & $73 \pm 12$ & $74 \pm 12$ & 0.827 \\
\hline Creatinine $(\mu \mathrm{mol} / \mathrm{l})$ & $75 \pm 16$ & $74 \pm 17$ & 0.052 \\
\hline eGFR (ml/min/1.73m²) & $90 \pm 16$ & $88 \pm 17$ & 0.003 \\
\hline Total cholesterol (mmol/l) & $5.3 \pm 1.2$ & $4.5 \pm 1.0$ & $<0.001$ \\
\hline HDL-cholesterol (mmol/l) & $1.26 \pm 0.36$ & $1.27 \pm 0.36$ & 0.433 \\
\hline LDL-cholesterol (mmol/l) & $3.4 \pm 1.0$ & $2.7 \pm 0.9$ & $<0.001$ \\
\hline Triacylglycerol (mmol/l) & $1.88 \pm 1.30$ & $1.70 \pm 1.11$ & $<0.001$ \\
\hline Glucose (mmol/l) & $7.6 \pm 2.3$ & $7.6 \pm 2.1$ & 0.747 \\
\hline $\mathrm{HbA}_{1 c}(\mathrm{mmol} / \mathrm{mol})$ & $49 \pm 14$ & $52 \pm 11$ & $<0.001$ \\
\hline $\mathrm{HbA}_{1 \mathrm{c}}(\%)$ & $6.7 \pm 1.2$ & $6.9 \pm 1.0$ & $<0.001$ \\
\hline Current smoking (\%) & 23.7 & 14.4 & $<0.001$ \\
\hline Former smoking (\%) & 42.5 & 51.1 & $<0.001$ \\
\hline$\%$ w. BP-lowering therapy & 35.7 & 63.4 & $<0.001$ \\
\hline$\%$ w. statins & 20.1 & 63.0 & $<0.001$ \\
\hline Skin autofluorescence (AU) & $2.25 \pm 0.50$ & $2.42 \pm 0.54$ & $<0.001$ \\
\hline SAF z score & $0.34 \pm 0.89$ & $0.56 \pm 0.99$ & $<0.001$ \\
\hline
\end{tabular}

Data are presented as mean $\pm S D$, number or $\%$ 


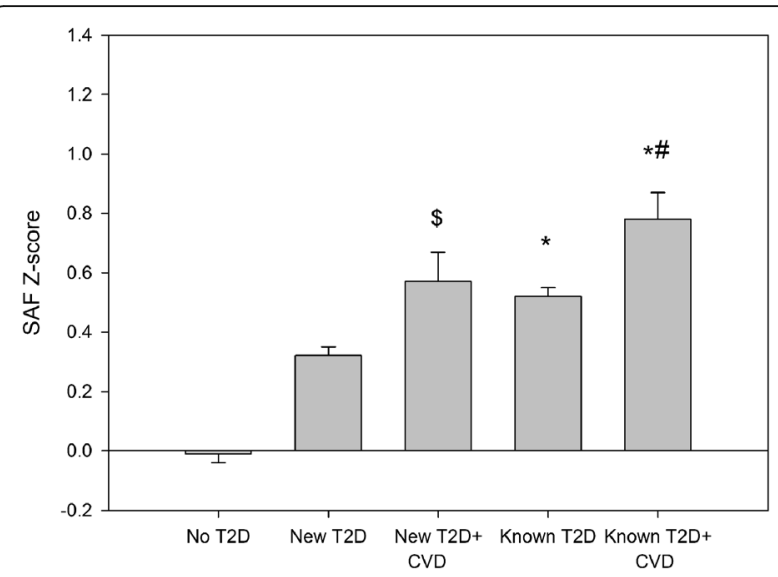

Fig. 1 Z-score of skin autofluorescence in relationship to presence of type 2 diabetes and cardiovascular disease. Data are presented as mean \pm SEM. For comparison, age-corrected SAF scores are compared with Lifelines participants without diabetes ('No T2D'). * denotes $p<0.001$ versus people with New T2D; $\$ p=0.009$ vs New T2D; \# $p<0.001$ vs Known T2D. All are $p<0.001$ vs No T2D

and glycaemic parameters were not significantly different. Incidence of cardiovascular disease was higher with increasing age, and was between 9.7 and 33\% in the highest age groups (Suppl. Fig. 2). Mean SAF Z-score at baseline was $0.70 \pm 1.11$ among the participants who developed a new CVD event vs $0.44 \pm 0.93$ in those who did not $(p=0.001)$.

Death occurred in 137 individuals (5.4\%). As expected, mortality was higher in older participants, and was between 5.5 and $52 \%$ in the highest age groups (Suppl. Fig. 2). Participants who deceased were older at baseline (67 \pm 12 vs $56 \pm 11$ yrs., $p<0.001)$, had lower eGFR (79 \pm 19 vs $\left.90 \pm 16 \mathrm{ml} / \mathrm{min} / 1.73 \mathrm{~m}^{2}, p<0.001\right)$, and more often renal impairment $\left(\mathrm{eGFR}<60 \mathrm{ml} / \mathrm{min} / 1.73 \mathrm{~m}^{2}, 18.5 \%\right.$ vs $4.1 \%, p<0.001)$. They also had higher SAF levels than individuals who remained alive: SAF Z-score was $0.81 \pm$ 1.06 in those who died vs $0.44 \pm 0.94$ in those who remained alive $(p<0.001)$.

Existing cardiovascular disease at baseline was strongly associated with outcome: incidence of new CVD events and death was significantly higher in participants with diabetes and CVD at baseline vs those with diabetes only, both in those with known and newly-detected diabetes (Table 2). Similarly, incidence of cardiovascular disease but not mortality was higher in those with known diabetes compared to those whose diabetes was detected at the baseline screening.

\section{Association and prediction}

Table 3 summarizes the univariable and multivariable associations between SAF and clinical, biochemical and lifestyle factors and the combined outcome of cardiovascular disease and mortality. Univariable analysis showed that SAF was significantly associated with combined outcome (OR 2.59, 95\% CI 2.10-3.20, $p=1.3 \times 10^{-18}$ ). Also, age, male sex, waist circumference, diastolic BP, heart rate, eGFR, as well as the use of BP-lowering medication and statins, and baseline CVD showed a significant association with the combined outcome. The association of SAF with outcome remained significant after adjusting for systolic BP, serum lipids, eGFR and glycaemic variables (OR 1.41, 95\% CI 1.10-1.82, $p=0.008$ ). In the multivariable model (Table 3), baseline cardiovascular disease, age, current smoking, SAF and systolic BP showed the strongest association with the combined outcome.

In Supplemental Table 1 we report the association between SAF and the individual outcomes. Univariable analyses showed SAF was significantly associated with mortality (OR 2.98, 95\% CI 2.25-3.94, $p=2.6 \times 10^{-14}$ ), as were age, sex, waist circumference, diastolic BP, eGFR, as well as BP-lowering therapy and baseline cardiovascular disease. This association remained significant after adjusting for all other baseline variables $(p=0.013)$. The multivariable model showed that SAF, age, systolic $\mathrm{BP}$, waist circumference, current smoking, statin use and baseline cardiovascular disease were independently associated with mortality. Comparable, SAF was also associated with new CVD events. In addition to SAF and age, other predictors for new CVD events were male sex, eGFR, diastolic BP and heart rate, as well as the use of statins, BP-lowering medication and baseline cardiovascular disease. SAF was no longer significant with incident cardiovascular disease in the multivariable models, in which age, current smoking and baseline cardiovascular disease showed the strongest association.

As baseline cardiovascular disease is a strong predictor of future CVD events and mortality, we re-calculated our models for the combined outcome of cardiovascular disease and mortality in participants without baseline cardiovascular disease. Again, SAF was strongly

Table 2 Incidence of CVD and death (percentage of participants) according to baseline diabetes and CVD status

\begin{tabular}{|c|c|c|c|c|c|c|}
\hline & $\begin{array}{l}\text { New T2D, no CVD } \\
(n=933)\end{array}$ & $\begin{array}{l}\text { New T2D, CVD } \\
(n=98)\end{array}$ & $P$-value & $\begin{array}{l}\text { Known T2D, no CVD } \\
(n=1138)\end{array}$ & $\begin{array}{l}\text { Known T2D, CVD } \\
(n=180)\end{array}$ & $P$-value \\
\hline New CVD events (\%) & $44(4.7 \%)$ & $25(25.5 \%)$ & $<0.001$ & $66(5.8 \%)$ & $60(33.3 \%)$ & $<0.001$ \\
\hline Death (\%) & $47(5.0 \%)$ & $16(16.3 \%)$ & $<0.001$ & $47(4.1 \%)$ & $27(15.0 \%)$ & $<0.001$ \\
\hline CVD or death (\%) & $88(9.4 \%)$ & $38(38.8 \%)$ & $<0.001$ & 110 (9.7\%) & 77 (42.8\%) & $<0.001$ \\
\hline
\end{tabular}


Table 3 Univariable and multivariable logistic regression analyses for the composite primary outcome (CVD or death) at a median of 3.7 years' follow-up

\begin{tabular}{|c|c|c|c|c|}
\hline Analysis & $\mathrm{n}$ & OR & $95 \% \mathrm{Cl}$ & $P$-value \\
\hline \multicolumn{5}{|l|}{ Univariable } \\
\hline SAF (AU) & 2349 & 2.59 & $2.10-3.20$ & $1.3 \times 10^{-18}$ \\
\hline Age (years) & 2349 & 1.06 & $1.05-1.08$ & $4.4 \times 10^{-25}$ \\
\hline Male sex $(y / n)$ & 2349 & 1.49 & $1.17-1.90$ & 0.001 \\
\hline BMI $\left(\mathrm{kg} / \mathrm{m}^{2}\right)$ & 2349 & 1.00 & $0.97-1.02$ & 0.697 \\
\hline Waist circumference (cm) & 2347 & 1.01 & $1.00-1.02$ & 0.025 \\
\hline Glucose (mmol/l) & 2333 & 0.99 & $0.94-1.05$ & 0.859 \\
\hline $\mathrm{HbA}_{1 \mathrm{c}}(\mathrm{mmol} / \mathrm{mol})$ & 2334 & 1.01 & $1.00-1.02$ & 0.092 \\
\hline $\mathrm{SBP}(\mathrm{mmHg})$ & 2343 & 1.00 & $0.99-1.00$ & 0.138 \\
\hline $\mathrm{DBP}(\mathrm{mmHg})$ & 2343 & 0.97 & $0.96-0.99$ & $5.2 \times 10^{-5}$ \\
\hline $\mathrm{HR}(/ \mathrm{min})$ & 2343 & 0.99 & $0.98-1.00$ & 0.013 \\
\hline Cholesterol (mmol/l) & 2341 & 0.91 & $0.82-1.01$ & 0.070 \\
\hline Triacylglycerol (mmol/l) & 2341 & 0.99 & 0.89-1.09 & 0.781 \\
\hline eGFR $\left(\mathrm{ml} / \mathrm{min} / 1.73 \mathrm{~m}^{2}\right)$ & 2342 & 0.97 & $0.97-0.98$ & $6.0 \times 10^{-14}$ \\
\hline Former smoking $(y / n)$ & 2335 & 1.30 & $1.02-1.64$ & 0.033 \\
\hline Current smoking $(\mathrm{y} / \mathrm{n})$ & 2335 & 1.19 & $0.89-1.60$ & 0.246 \\
\hline Statin $(y / n)$ & 2349 & 1.44 & $1.14-1.83$ & 0.002 \\
\hline BP-lowering therapy $(y / n)$ & 2349 & 2.28 & $1.77-2.94$ & $1.7 \times 10^{-10}$ \\
\hline Baseline CVD (y/n) & 2349 & 6.67 & $5.04-8.83$ & $2.8 \times 10^{-40}$ \\
\hline Multivariable model 1 & 2310 & & & \\
\hline SAF (AU) & & 1.41 & $1.10-1.82$ & 0.008 \\
\hline Age (years) & & 1.05 & $1.03-1.07$ & $5.9 \times 10^{-8}$ \\
\hline Male sex (y/n) & & 1.16 & $0.84-1.62$ & 0.368 \\
\hline BMI $\left(\mathrm{kg} / \mathrm{m}^{2}\right)$ & & 0.96 & $0.90-1.01$ & 0.126 \\
\hline Waist (cm) & & 1.02 & $1.00-1.05$ & 0.031 \\
\hline Glucose (mmol/l) & & 0.99 & $0.90-1.08$ & 0.784 \\
\hline $\mathrm{HbA1c}(\mathrm{mmol} / \mathrm{mol})$ & & 1.01 & $1.00-1.03$ & 0.124 \\
\hline $\mathrm{SBP}(\mathrm{mmHg})$ & & 0.99 & $0.98-1.00$ & 0.051 \\
\hline $\mathrm{DBP}(\mathrm{mmHg})$ & & 0.99 & $0.97-1.01$ & 0.411 \\
\hline $\mathrm{HR}(/ \mathrm{min})$ & & 1.01 & $1.00-1.02$ & 0.081 \\
\hline Cholesterol (mmol/l) & & 1.08 & $0.93-1.25$ & 0.331 \\
\hline Triacylglycerol (mmol/l) & & 1.01 & $0.89-1.15$ & 0.848 \\
\hline eGFR $\left(\mathrm{ml} / \mathrm{min} / 1.73 \mathrm{~m}^{2}\right)$ & & 1.00 & $0.99-1.01$ & 0.845 \\
\hline Former smoking $(y / n)$ & & 0.95 & $0.69-1.30$ & 0.738 \\
\hline Current smoking $(\mathrm{y} / \mathrm{n})$ & & 1.69 & $1.13-2.53$ & 0.010 \\
\hline Statin $(y / n)$ & & 0.72 & $0.51-1.01$ & 0.054 \\
\hline BP-lowering therapy $(y / n)$ & & 1.33 & $0.97-1.82$ & 0.075 \\
\hline Baseline CVD (y/n) & & 5.25 & $3.71-7.42$ & $7.4 \times 10^{-21}$ \\
\hline Multivariable model 2 & 2327 & & & \\
\hline SAF (AU) & & 1.48 & $1.15-1.90$ & 0.002 \\
\hline Age (years) & & 1.06 & $1.04-1.07$ & $8.2 \times 10^{-14}$ \\
\hline Waist (cm) & & 1.02 & $1.00-1.02$ & 0.005 \\
\hline SBP $(m m H g)$ & & 0.99 & $0.98-1.00$ & 0.003 \\
\hline
\end{tabular}


Table 3 Univariable and multivariable logistic regression analyses for the composite primary outcome (CVD or death) at a median of 3.7 years' follow-up (Continued)

\begin{tabular}{|c|c|c|c|c|}
\hline Analysis & $\mathbf{n}$ & OR & $95 \% \mathrm{Cl}$ & $P$-value \\
\hline Current smoking $(\mathrm{y} / \mathrm{n})$ & & 1.83 & $1.31-2.56$ & $4.4 \times 10^{-4}$ \\
\hline Statin $(y / n)$ & & 0.70 & $0.53-0.94$ & 0.016 \\
\hline Baseline CVD (y/n) & & 5.30 & $3.84-7.33$ & $4.8 \times 10^{-2}$ \\
\hline
\end{tabular}

Baseline risk factors were used to predict the median 3.7 year risk of the composite outcome of new CVD events and death

$\mathrm{SAF}$, age, glucose, $\mathrm{HbA}_{1 c}$, waist circumference, systolic and diastolic BP, HR, cholesterol, triacylglycerol and eGFR were defined as continuous variables. Male sex, current smoking, statin use, use of BP-lowering therapy and baseline CVD were defined as categorical variables

$\mathrm{DBP}$, diastolic BP; SBP, systolic BP; HR, heart rate; $y / n$, yes/no

associated with the combined outcome, even when adjusted for the other variables age, systolic BP, waist circumference, statin use and current smoking (Supplemental Table 2).

\section{Discussion}

In a previous study in the general population, we have shown that skin autofluorescence is strongly associated with new-onset of type 2 diabetes and cardiovascular disease as well as mortality. This association was independent of cardiovascular risk factors like age, sex, waist circumference, smoking, and glycaemic parameters. In the present study we show that SAF is also significantly and independently associated with the combined outcome of new CVD events and mortality in people with type 2 diabetes.

It has long been known that the formation of AGEs is increased in people with diabetes as a consequence of high glucose levels and oxidative stress [8, 27]. Earlier, we have shown that SAF levels are increased in people with the metabolic syndrome, a cluster of risk factors which is associated with an increased risk of both type 2 diabetes and cardiovascular disease [28]. However, when adjusted for presence of the metabolic syndrome, SAF levels were an independent predictor of new type 2 diabetes in the general population [22]. Our current analyses shows that individuals with newly-detected type 2 diabetes had lower SAF Z-scores than those with known type 2 diabetes, indicating the longer period of exposure to elevated glucose levels in people with longer-standing diabetes. In addition, participants with cardiovascular disease had higher SAF levels, both those with newlydetected and those with known diabetes (Fig. 1). Existing cardiovascular disease was the strongest predictor for future CVD events and mortality. Nevertheless, SAF was associated with this combined outcome independently of factors like existing cardiovascular disease, age, smoking, lipid or BP levels.

SAF was associated with a threefold increased mortality risk, and this association remained highly significant after adjusting for several confounding factors (Supplemental Table 1). This confirms our earlier observations in people without diabetes [22]. In that study a high odds ratio for mortality was also obtained when modelling with the linear method based on the entire population without diabetes or cardiovascular disease. Similarly, SAF was associated with an increased risk of new CVD events. Several earlier reports have described the cross-sectional relationship between SAF and the presence and development of vascular complications in type 2 diabetes. Prospective studies evaluating the predictive value of SAF measurements were performed in selected patient populations [17, 20,21]. SAF did predict cardiac mortality in people with diabetes [29] and in patients on chronic haemodialysis [30-32], and predicted the occurrence of cardiovascular events and mortality in individuals with peripheral vascular disease [33]. In addition, SAF predicted the subsequent need for limb amputation, which was independent of disease status, and proved to be additive to the predictive value of the Fontaine classification [34].

Our findings support the clinical utility of SAF to support risk assessment for cardiovascular disease and mortality, both in the general population and in people with type 2 diabetes. As suggested earlier [22], SAF measurement is relatively fast and non-invasive, and can therefore also be used outside a G.P. practice or hospital such as in pharmacies as a first estimate of risk. The present data also confirm that both current smoking and presence of cardiovascular disease are strong predictors for future CVD events and mortality, supporting aggressive intervention for smoking cessation as well as optimizing efforts to reduce cardiovascular disease burden. The fact that in the current study only $63 \%$ of people with known type 2 diabetes were using statins, and mean LDLcholesterol was above the desired target suggests that improvements in cardiovascular risk factor intervention are desirable [35].

\section{Strengths and limitations}

We presented data from a population-based study that included over 2300 participants with type 2 diabetes. The Lifelines Cohort Study has no follow-up data available on the use of new glucose-lowering or other medications or changes in medications, which could be used to confirm new CVD events and could influence the 
subsequent clinical course. New diagnosis of type 2 diabetes could only be based on a single blood glucose or HbA1c measurement. The current dataset of lifelines does not allow to perform survival analysis. The study included mainly participants from Western European background, and therefore our results may not be generalizable to other ethnic populations. Data on the exact cause of death may be helpful in further refining the predictive power of SAF.

\section{Conclusions}

In conclusion, we showed that skin autofluorescence measurements significantly predicted new CVD events and mortality in people with type 2 diabetes independently of conventional cardiovascular risk factors. The Lifelines study is still ongoing, and a longer follow-up of its participants will expand the current evaluations and allow further validation.

\section{Supplementary Information}

The online version contains supplementary material available at https://doi. org/10.1186/s12902-020-00676-4

Additional file 1: Figure S1. Flow chart indicating the disposition of participants.

Additional file 2: Figure S2. Incidence of CVD events and death according to age.

Additional file 3: Table S1. Univariable and multivariable logistic regression analyses for the separate primary outcomes (CVD or death) at a median of 3.7 year follow-up.

Additional file 4: Table S2. Univariable and multivariable logistic regression analyses for the composite primary outcome (CVD or death) at a median of 3.7 years' follow-up of people with baseline type 2 diabetes without clinically-manifest CVD.

\section{Abbreviations}

AGE: Advanced glycation endproducts; AU: Arbitrary units; BMl: Body mass index; CVD: Cardiovascular disease; DBP: Diastolic BP; eGFR: Estimated glomerular filtration rate; HbA1c: Glycated haemoglobin; HR: Heart rate: IQR: Interquartile range; SAF: Skin autofluorescence; SBP: Systolic BP; T2D: Type 2 diabetes

\section{Acknowledgements}

The authors would like to acknowledge all the study participants, services of the Lifelines Cohort Study and the contributing research centres delivering data to Lifelines.

\section{Authors' contributions}

HEB, RPVW, MMvdK and BHRW designed the study. HEB and BHRW performed the statistical analyses. HEB, RPvW, MMvK, RG, ADP, AJS and BHRW contributed to the analyses and interpreted the data. HEB drafted the initial version of the manuscript, which was revised by all authors. The final versions of the manuscript was approved by all authors. BHRW is the guarantor of this work.

\section{Funding}

The Lifelines Biobank initiative has been made possible by subsidy from the Dutch Ministry of Health, Welfare and Sport, the Dutch Ministry of Economic Affairs, the University Medical Center Groningen (UMCG the Netherlands), University Groningen and the Northern Provinces of the Netherlands. The funders had no role in study design, data collection and analysis, decision to publish, or preparation of the manuscript.

\section{Availability of data and materials}

The manuscript is based on data from the Lifelines Cohort Study. Lifelines adheres to standards for data availability, and allows access for reproducibility of the study results. The data catalogue of Lifelines is publicly accessible at www.lifelines.nl. The dataset supporting the conclusions of this article is available through the Lifelines organisation (e-mail: research@lifelines.nl). For data access, a fee is required.

\section{Ethics approval and consent to participate}

This study was approved by the medical ethical review committee of the University Medical Center Groningen. All participants provided written informed consent before participating in the study.

\section{Consent for publication}

Not applicable.

\section{Competing interests}

RG and AJS are founders and shareholders in Diagnoptics Technologies (Groningen, the Netherlands), manufacturer of the AGE Reader. The other authors declare that they have no competing interests.

\section{Author details}

'Department of Endocrinology, University of Groningen, University Medical Center Groningen, P.O. Box 30001, HPC AA31, Groningen, RB 9700, The Netherlands. ${ }^{2}$ Department of Internal Medicine, University of Groningen, University Medical Center Groningen, Groningen, The Netherlands. 'P Program in Genetics and Genome Biology, Hospital for Sick Children, Toronto, ON, Canada.

Received: 1 September 2020 Accepted: 30 December 2020

Published online: 12 January 2021

\section{References}

1. Wolffenbuttel BHR, Van Haeften TW. Prevention of complications in noninsulin-dependent diabetes mellitus (NIDDM). Drugs. 1995;50(2):263-88.

2. Brownlee $M$. The pathobiology of diabetic complications: a unifying mechanism. Diabetes. 2005;54(6):1615-25.

3. Ford ES. Trends in the risk for coronary heart disease among adults with diagnosed diabetes in the U.S.: findings from the National Health and Nutrition Examination Survey, 1999-2008. Diabetes Care. 2011;34(6):1337-43.

4. Lindstrom J, Tuomilehto J. The diabetes risk score: a practical tool to predict type 2 diabetes risk. Diabetes Care. 2003;26(3):725-31.

5. Conroy RM, Pyorala K, Fitzgerald AP, Sans S, Menotti A, De Backer G, et al. Estimation of ten-year risk of fatal cardiovascular disease in Europe: the SCORE project. Eur Heart J. 2003:24(11):987-1003.

6. D'Agostino RB Sr, Vasan RS, Pencina MJ, Wolf PA, Cobain M, Massaro JM, et al. General cardiovascular risk profile for use in primary care: the Framingham Heart Study. Circulation. 2008;117(6):743-53.

7. Noble D, Mathur R, Dent T, Meads C, Greenhalgh T. Risk models and scores for type 2 diabetes: systematic review. BMJ. 2011;343:d7163.

8. Monnier VM. Nonenzymatic glycosylation, the Maillard reaction and the aging process. J Gerontol. 1990;45(4):B105-11.

9. Brownlee M. Advanced protein glycosylation in diabetes and aging. Annu Rev Med. 1995;46:223-34.

10. Baynes JW, Thorpe SR. Glycoxidation and lipoxidation in atherogenesis. Free Radic Biol Med. 2000;28(12):1708-16.

11. Aronson D. Cross-linking of glycated collagen in the pathogenesis of arterial and myocardial stiffening of aging and diabetes. J Hypertens. 2003;21(1):312

12. Liu CY, Huang QF, Cheng YB, Guo QH, Chen Q, Li Y, et al. A Comparative Study on Skin and Plasma Advanced Glycation End Products and Their Associations with Arterial Stiffness. Pulse (Basel). 2017;4(4):208-18.

13. Basta G, Schmidt AM, De Caterina R. Advanced glycation end products and vascular inflammation: implications for accelerated atherosclerosis in diabetes. Cardiovasc Res. 2004;63(4):582-92.

14. Isermann B, Bierhaus A, Humpert PM, Rudofsky G, Chavakis T, Ritzel R, et al. AGE-RAGE: A Hypothesis or a Mechanism? Herz. 2004;29(5):504-9.

15. Meerwaldt R, Graaff R, Oomen PHN, Links TP, Jager JJ, Alderson NL, et al. Simple non-invasive assessment of advanced glycation endproduct accumulation. Diabetologia. 2004;47(7):1324-30. 
16. Meerwaldt R, Links T, Graaff R, Thorpe SR, Baynes JW, Hartog J, et al. Simple noninvasive measurement of skin autofluorescence. Ann N Y Acad Sci. 2005; 1043:290-8

17. Lutgers HL, Graaff R, Links TP, Ubink-Veltmaat L, Bilo HJ, Gans RO, et al. Skin autofluorescence as a noninvasive marker of vascular damage in patients with type 2 diabetes. Diabetes Care. 2006;29(12):2654-9.

18. Koetsier M, Lutgers HL, de Jonge C, Links TP, Smit AJ, Graaff R. Reference values of skin autofluorescence. Diabetes Technol Ther. 2010;12(5):399-403.

19. Gerrits EG, Lutgers HL, Kleefstra N, Graaff R, Groenier KH, Smit AJ, et al. Skin autofluorescence: a tool to identify type 2 diabetic patients at risk for developing microvascular complications. Diabetes Care. 2008;31(3):517-21.

20. Noordzij MJ, Mulder DJ, Oomen PH, Brouwer T, Jager J, Castro Cabezas M, et al. Skin autofluorescence and risk of micro- and macrovascular complications in patients with Type 2 diabetes mellitus-a multi-centre study. Diabet Med. 2012;29(12):1556-61.

21. Tanaka K, Tani Y, Asai J, Nemoto F, Kusano Y, Suzuki H, et al. Skin autofluorescence is associated with severity of vascular complications in Japanese patients with Type 2 diabetes. Diabet Med. 2012;29(4):492-500.

22. van Waateringe RP, Fokkens BT, Slagter SN, van der Klauw MM, van VlietOstaptchouk JV, Graaff R, et al. Skin autofluorescence predicts incident type 2 diabetes, cardiovascular disease and mortality in the general population. Diabetologia. 2019;62(2):269-80.

23. Stolk RP, Rosmalen JG, Postma DS, de Boer RA, Navis G, Slaets JP, et al. Universal risk factors for multifactorial diseases: LifeLines: a three-generation population-based study. Eur J Epidemiol. 2008;23(1):67-74.

24. Scholtens S, Smidt N, Swertz MA, Bakker SJ, Dotinga A, Vonk JM, et al. Cohort Profile: LifeLines, a three-generation cohort study and biobank. Int J Epidemiol. 2015;44(4):1172-80.

25. Koetsier M, Nur E, Chunmao H, Lutgers HL, Links TP, Smit AJ, et al. Skin color independent assessment of aging using skin autofluorescence. Opt Express. 2010;18(14):14416-29.

26. Levey AS, Stevens $L A$, Schmid CH, Zhang YL, Castro AF, Feldman Hl, et al. A new equation to estimate glomerular filtration rate. Ann Intern Med. 2009; 150(9):604-12.

27. Dyer DG, Dunn JA, Thorpe SR, Bailie KE, Lyons TJ, McCance DR, et al. Accumulation of Maillard reaction products in skin collagen in diabetes and aging. J Clin Invest. 1993;91(6):2463-9.

28. van Waateringe RP, Slagter SN, van Beek AP, van der Klauw MM, van VlietOstaptchouk JV, Graaff R, et al. Skin autofluorescence, a non-invasive biomarker for advanced glycation end products, is associated with the metabolic syndrome and its individual components. Diabetol Metab Syndr. 2017;9:42.

29. Meerwaldt R, Lutgers HL, Links TP, Graaff R, Baynes JW, Gans RO, et al. Skin autofluorescence is a strong predictor of cardiac mortality in diabetes. Diabetes Care. 2007;30(1):107-12.

30. Meerwaldt R, Hartog JW, Graaff R, Huisman RJ, Links TP, den Hollander NC, et al. Skin autofluorescence, a measure of cumulative metabolic stress and advanced glycation end products, predicts mortality in hemodialysis patients. J Am Soc Nephrol. 2005;16(12):3687-93.

31. Fraser SD, Roderick PJ, Mclntyre NJ, Harris S, Mclntyre CW, Fluck RJ, et al. Skin autofluorescence and all-cause mortality in stage 3 CKD. Clin J Am Soc Nephrol. 2014;9(8):1361-8.

32. Macsai E, Benke A, Kiss I. Skin Autofluorescence and Mortality in Patients on Peritoneal Dialysis. Medicine (Baltimore). 2015;94(45):e1933.

33. de Vos LC, Mulder DJ, Smit AJ, Dullaart RP, Kleefstra N, Lijfering WM, et al. Skin autofluorescence is associated with 5-year mortality and cardiovascular events in patients with peripheral artery disease. Arterioscler Thromb Vasc Biol. 2014;34(4):933-8.

34. de Vos LC, Boersema J, Mulder DJ, Smit AJ, Zeebregts CJ, Lefrandt JD. Skin autofluorescence as a measure of advanced glycation end products deposition predicts 5 -year amputation in patients with peripheral artery disease. Arterioscler Thromb Vasc Biol. 2015;35(6):1532-7.

35. Fruchart JC, Davignon J, Hermans MP, Al-Rubeaan K, Amarenco P, Assmann $\mathrm{G}$, et al. Residual macrovascular risk in 2013: what have we learned? Cardiovasc Diabetol. 2014;13:26.

\section{Publisher's Note}

Springer Nature remains neutral with regard to jurisdictional claims in published maps and institutional affiliations.

\section{Ready to submit your research? Choose BMC and benefit from:}

- fast, convenient online submission

- thorough peer review by experienced researchers in your field

- rapid publication on acceptance

- support for research data, including large and complex data types

- gold Open Access which fosters wider collaboration and increased citations

- maximum visibility for your research: over $100 \mathrm{M}$ website views per year

At BMC, research is always in progress.

Learn more biomedcentral.com/submissions 